\title{
Repair and maintenance costs of hill-farm tractors and transporters for upland mechanisation
}

\author{
Markus Lips \\ Agroscope Reckenholz Tänikon Research Station ART, Ettenhausen, Switzerland
}

\begin{abstract}
The annual repair and maintenance costs of two types of motorised agricultural machines for upland agriculture, hill-farm tractors (twoaxle mowers) and transporters, are estimated on the basis of crosssectional data. An aggregation leads to the accumulated repair and maintenance costs for the entire service life of the machines, expressed as a repair and maintenance factor (RMF). Given the strong influence of annual utilisation, a high annual utilisation combined with a short length of service leads to lower accumulated costs. While the RMFs of hill-farm tractors and transporters are similar, they are higher than those of standard 4-wheel drive tractors analysed in a similar study. This effect is especially relevant for low annual utilisation, as is the case for both machine types under current operating conditions in Switzerland. Accordingly, the assumption that the RMFs of hillfarm tractors and transporters are equivalent to those of standard 4wheel drive tractors is not to be recommended.
\end{abstract}

\section{Introduction}

Besides taking depreciation, interest rate, insurance, housing and fuel into account, machinery costs also consist of repair and maintenance costs. Because they tend to increase with the age of the machine (Rotz, 1987), repair and maintenance costs represent a sig-

Correspondence: Markus Lips, Farm Management Research Group, Agroscope Reckenholz Tänikon Research Station ART, 8356 Ettenhausen, Switzerland.

E-mail: markus.lips@agroscope.admin.ch

Key words: agricultural machines, machinery costs, estimated service life, Switzerland, regression analysis.

Acknowledgements: the author would like to thank Frank Burose and Victor Anspach for data preparation, as well as the two reviewers for their very helpful comments.

Received for publication: 19 September 2013.

Accepted for publication: 29 November 2013.

CC Copyright Markus Lips, 2013

Licensee PAGEPress, Italy

Journal of Agricultural Engineering 2013; XLIV:e19

doi:10.4081/jae.2013.e19

This article is distributed under the terms of the Creative Commons Attribution Noncommercial License (by-nc 3.0) which permits any noncommercial use, distribution, and reproduction in any medium, provided the original author(s) and source are credited. nificant handicap. In order to provide easy-to-apply figures for farm management literature, repair and maintenance factors (RMFs) indicating the total accumulated repair and maintenance costs for the entire useful life of the machinery in question are given as a fraction of the machine's list price. As an example, an RMF of 0.6 for a standard tractor with a list price of 100,000 Swiss Francs (CHF 100,000) indicates accumulated repair and maintenance costs of CHF 60,000 accruing during the machine's estimated service life (also called its estimated life) that is normally assumed to be 10,000 hours (h). The hourly repair and maintenance costs would, therefore, amount to CHF 6.00. While most analyses of repair and maintenance costs focus on tractors (Ward et al., 1985; Morris, 1988; Wendel, 1989; Bruhn, 2000; Khoub bakht et al., 2008; Calcante et al., 2013), as far as we are aware, no analyses are available for specific motorised agricultural machines used in upland agriculture. When listing repair and maintenance costs for a wide range of agricultural machinery, the American Society of Agricultural and Biological Engineers (ASABE) only distinguishes between 2- and 4-wheel drive (4WD) tractors (ASAE, 2003a).

In addition to using standard $4 \mathrm{WD}$ tractors, agricultural mechanisation in Swiss hill and mountain regions relies on hill-farm tractors (two-axle mowers) and transporters for upland mechanisation. Both are equipped with $4 \mathrm{WD}$, and are suitable for use on sloping terrain. Both, moreover, are frequently equipped with dual wheels. Hill-farm tractors (Figure 1) have a particularly low centre of gravity, a widened wheelbase, and options for mounting machinery at the front and rear (Eichhorn, 1999). They are especially suitable for operating mowers. Different machines and implements can be mounted on transporters for upland mechanisation, the most common being self-loading trailers, solid-manure spreaders and slurry tankers (Figure 2). Due to specific technical requirements, and the typically small-scale serial production of hill-farm tractors and transporters for upland mechanization, these machines are more expensive than standard 4WD tractors. Here, the cost per kW engine power can be used as a basis for comparison. On average, the list price of standard $4 \mathrm{WD}$ tractors up to $70 \mathrm{~kW}$ shows costs of CHF 1295 per kW (Gazzarin and Albisser, 2010). By contrast, average costs per kW are to CHF 2088 and CHF 1910 for hill-farm tractors and transporters, respectively. As regards machinery-cost calculation, there is the question of whether the RMFs of hill-farm tractors and transporters for upland mechanisation differ from the figures for standard tractors. If no differences (or only minor ones) are found, it would be recommended to assume the RMF for standard 4WD tractors. Using cross-sectional data from a survey, this paper analyses repair and maintenances costs for both upland-agriculture machine types, and compares these costs to the RMFs of standard 4WD tractors given in a similar analysis (Lips and Burose, 2012).

\section{Materials and methods}

To analyse the repair and maintenance costs of hill-farm tractors and transporters for upland mechanisation, we use the same approach 
as that outlined in Lips and Burose (2012) and Lips (2013). The approach consists of two steps. Firstly, a regression analysis of the annual repair and maintenance costs based on cross-sectional data is performed. The machinery data collected from a farm survey, therefore, only covers the repair and maintenance costs of one or several years, unlike the accumulated data necessary for the frequently applied approach of Bowers and Hunt (1970) or the American Society of Agricultural and Biological Engineers (ASAE, 2003a, 2003b). Secondly, an aggregation of annual costs towards the accumulated repair and maintenance cost, expressed as RMF, is carried out.

The annual repair and maintenance costs are divided with reference to the machine type's current list price that reflects machine size (ASAE, 2003b). Having positive values of close to zero, the dependent variable of the regression has a skewed distribution for both machine types. Consequently, a logarithmic transformation is applied. For the regression analysis, power form and exponential functional forms are used. Due to an underperformance of the exponential form in terms of the coefficient of determination $\left(\mathrm{R}^{2}\right)$, we focus on the power functional form (Equation 1):

$$
y=\beta_{0} x_{1}^{\beta_{1}} x_{2}^{\beta_{2}}
$$

The dependent variable $y$ represents the annual repair and maintenance costs expressed as a fraction of the machine's list price, while the independent variables $x_{1}$ and $x_{2}$ refer to annual utilisation and age, respectively. The coefficients $e_{1}$ and ${ }_{2}$ are estimated. Due to the logarithmic transformation, the econometric estimation is performed in the following manner (Equation 2):

$$
\ln y=\ln \beta_{0}+\beta_{1} \ln x_{1}+\beta_{2} \ln x_{2}
$$

For the estimation (Eq. 2), the weighted ordinary least squares (OLS) approach is applied. The weights result from the iteratively reweighted least squares (IRLS) robust regression, which takes into account potential outliers. The Breusch-Pagan test is then used to analyse whether the variance of the regression residuals is constant.
This is the case for both machine types. Starting with all available variables, the exclusion of variables is analysed by means of F-tests.

An aggregation of the annual repair and maintenance costs $y_{i}$ for all the years $i$ in service of the machine is required in order to obtain the RMF (Equation 3):

$$
R M F=\sum_{i=1}^{L S} y_{i}
$$

For this, we assume that the machine's estimated service life $u$ (e.g. 10,000 hours for transporters) is completely utilized. We think of $u$ as the product of the annual utilization $x_{l}$ (expressed in hours) and a reference length of service $L S$ (expressed in years; $u=x_{1} * L S$ ).

Inserting Equation 1 in Equation 3 yields the following:

$$
R M F=\beta_{0} x_{1}^{\beta_{1}} \sum_{i=1}^{L S} x_{2 i}^{\beta_{2}}
$$

To illustrate the influence of operating conditions, several annual utilisations and matched lengths of service are provided (e.g. $400 \mathrm{~h}$ over 25 years $v s 333$ h over 30 years). Since the aggregation occurs on an annual basis, $L S$ must be an integer.

\section{Data}

Albisser et al. (2009) conducted a postal cross-sectional survey on machinery costs in Switzerland in the final months of 2008. A total of 2000 farms were randomly selected: 1000 arable or combined arable/dairy farms in the plain region, and 1000 dairy farms in the hill and mountain regions. Respective response rates for the two subsamples were $20 \%$ and $15 \%$. The survey included three types of motorised machines: tractors, hill-farm tractors, and transporters for upland mechanisation. While the bulk of the hill-farm tractors and transporters for upland mechanisation were derived from the hill and mountain region subsample, farms from the plain-region subsample also reported such machine types.

The survey asked farmers to give repair costs, including service agents' bills, for the last three years for each machine. The question-

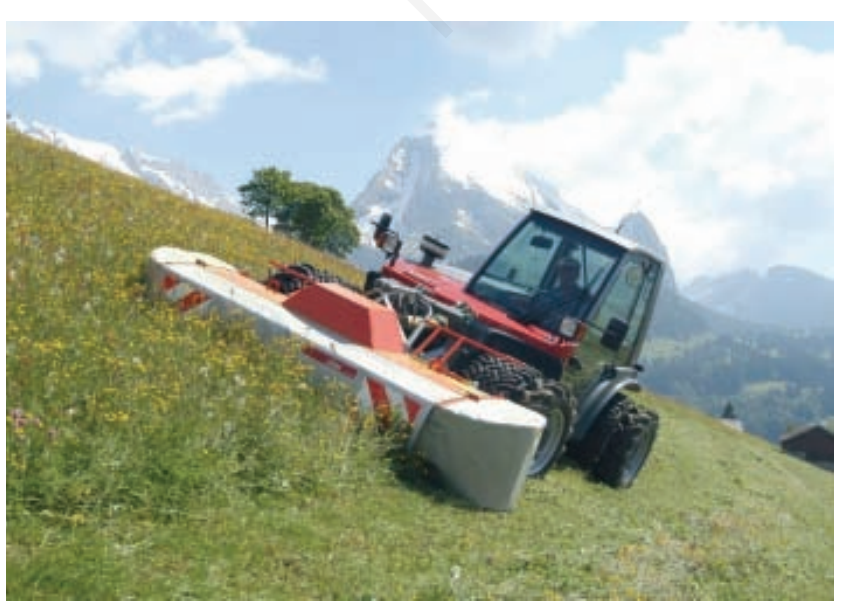

Figure 1. Hill-farm tractor (photo courtesy of Aebi \& Co. AG Maschinenfabrik).

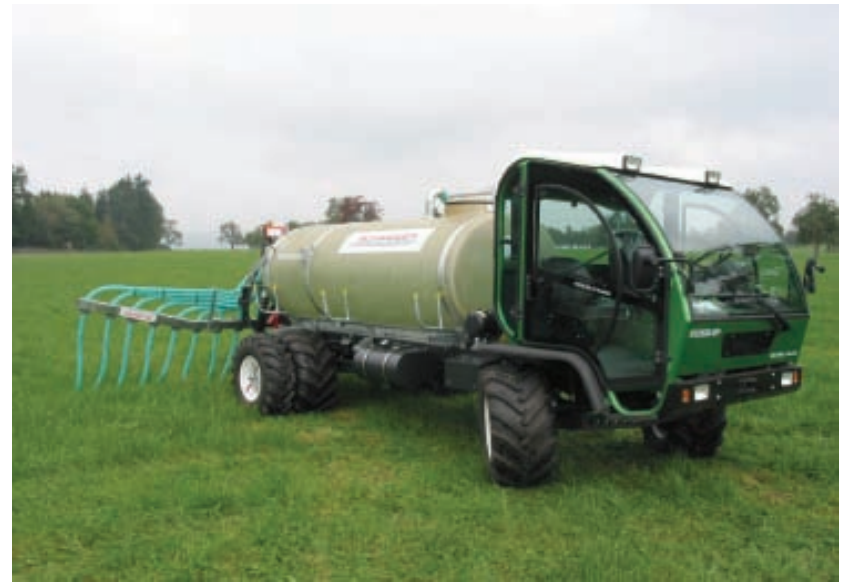

Figure 2. Transporter for upland mechanisation with mounted slurry tanker (photo courtesy of Schweizer AG). 
naire provided space for details of up to nine repairs. Although repair work requires specialist training, the performance of jobs of this nature on-farm cannot be ruled out. The cost of the materials used was also taken into account. Unfortunately, the survey did not include farmemployee labour input for on-farm repairs. In the current study, the resulting underestimation of repair costs must, therefore, be borne in mind in our discussion and conclusions.

For maintenance activities, the survey took annual material costs and farm-employee labour input into account. For three machines, the number of annual hours of maintenance performed by farm employees was missing. In order to keep these machines in the analysed sample, we inserted one hour of maintenance activity per year as a minimum value. Labour input was multiplied by CHF 27, the recommended hourly agricultural wage in the year of the survey (Ammann, 2007). Consequently, the values reported in CHF are not converted into Euros.

Both maintenance costs and annual mean repair costs were then added together. For the above-mentioned breakdown according to machinery list price, the machinery-cost report from 2010 (Gazzarin and Albisser, 2010) was used, bearing in mind the specific size of machine measured in $\mathrm{kW}$. Since the survey was carried out in 2008 and the time of writing (November 2013), the exchange rate between the Euro and the Swiss Franc (CHF) changed substantially, increasing by approximately $30 \%$ (Table 1 ).

Some machines had to be excluded from the analysis, owing to data gaps in the essential information of age and annual utilisation. All in all, data from 64 hill-farm tractors and 54 transporters for upland mechanisation were available for the analysis (Table 1).

Table 1 sets out machine-specific key figures such as average list prices and engine power, and includes the coefficient of variation (CV) as an indication of the distribution. Hill-farm tractors have a markedly lower average age than transporters. Whereas the first hill-farm tractors were introduced 30 years ago, transporters were introduced earlier. Accordingly, the sample also includes some very old machines, with 12 out of 54 transporters being over 30 years of age. In fact, three of the transporters have been in service for 40 years or more. Accordingly, some of the sample's machines are technically obsolescent.

The estimated service life of transporters $(10,000 \mathrm{~h})$ is the same as for standard 4WD tractors, an important pre-condition for the subsequent comparison of repair and maintenance costs. As for the estimated service life of hill-farm tractors, it should be noted that the machinery report (Gazzarin and Albisser, 2010) distinguishes between four classes of hill-farm tractors: $30,35,45$ and $65 \mathrm{~kW}$, respectively. While the two smaller classes have a service life of $8000 \mathrm{~h}$, the service life of the remaining two classes is $10,000 \mathrm{~h}$. Since the average engine power is closest to that of the first class, we use a service life of $8000 \mathrm{~h}$.

The theoretical length of service is calculated under the assumption that the observed annual utilisation is representative of the entire lifespan. For hill-farm tractors, the length of service would be 39.4 years ( $=8000 \mathrm{~h}$ estimated service life divided by an annual utilisation of 203 h). For transporters, the length of service would be 54.6 years. Accordingly, these figures show the unlikelihood that the technical potential of both machine types will be fully utilised under Swiss agriculture's current operating conditions, also bearing in mind that innovations occur within shorter periods owing to technical progress.

In terms of maintenance activities, annual farm-employee labour is divided according to annual utilization (Table 1). For both machine types, the mean values amount to $0.11 \mathrm{~h}$ per hour of operation. The coefficients of variation, both of which exceed 1, highlight the diversity of the maintenance activities.

\section{Results}

Table 2 sets out the regression estimates for annual repair and maintenance costs, expressed as a fraction of the machine's list price. The coefficients of determination $\left(\mathrm{R}^{2}\right)$ for hill-farm tractors and transporters are 0.29 and 0.33 , respectively. According to the F-test for both machine types, we can obviously reject the hypothesis that the estimated coefficients are simultaneously equal to zero. In each regression, one observation is identified as a statistical outlier and excluded (robust regression).

For both machine types, annual utilisation is reported to have a significant impact on annual repair and maintenance costs. The two referring coefficients for hill-farm tractors and transporters $(0.59$ and 0.57 , respectively) are clearly below one. Given the power-function form, this means that annual repair and maintenance costs increase subproportionally with increased utilisation. Age too has a significant impact on annual costs. The effect is stronger for hill-farm tractors, with almost double the coefficient for transporters.

Table 3 reports the results of RMFs for different operating conditions (annual utilisation and matched lengths of service in years). In all

Table 1. Key figures for hill-farm tractors and transporters for upland mechanisation.

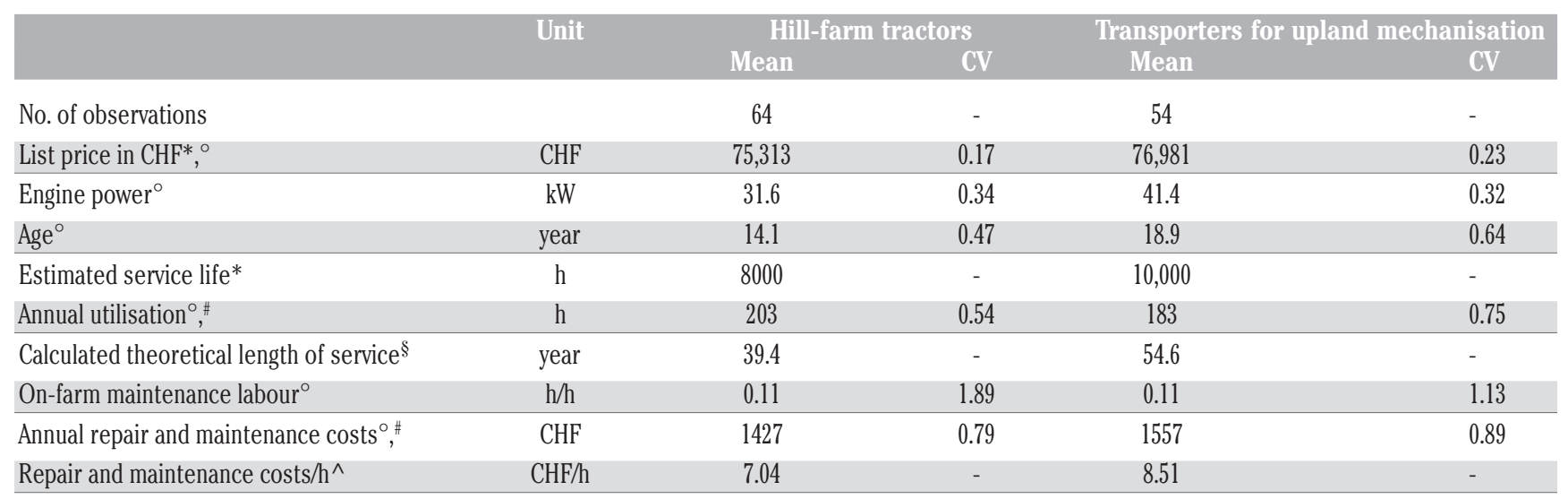

$\mathrm{CV}$, coefficients of variation (CV) are indicated for all key figures except those which are either assumed (estimated service life) or calculated on the basis of sample mean values. CH, Swiss Francs; average exchange rate 2008: $1 \mathrm{CHF}=0.63$ Euro; average exchange rate for November 2013: $1 \mathrm{CHF}=0.81$ Euro; (http://fxtop.com accessed 19 September 2013). *Based on Gazzarin and Albisser (2010); ${ }^{\circ}$ Mean value of machine-type observations, based on the survey by Albisser et al. (2009); "Based on a 3-year average, 2006-2008; §Estimated service life in hours divided by annual utilisation; ^Annual repair and maintenance costs divided by annual utilisation. 
cases, a full utilisation of estimated service life is assumed. For hillfarm tractors, the results are presented for service lives of 8000 and $10,000 \mathrm{~h}$, respectively. While $8000 \mathrm{~h}$ refers to the average of the analysed sample (31.6 kW, Table 1), the estimated coefficients are also assumed to be valid for hill-farm tractors with greater engine power (e.g. 45 and $65 \mathrm{~kW})$.

While Table 3 reports the RMF for the full estimated service life, Figures 3 and 4 set out the pathways of the accumulated repair and

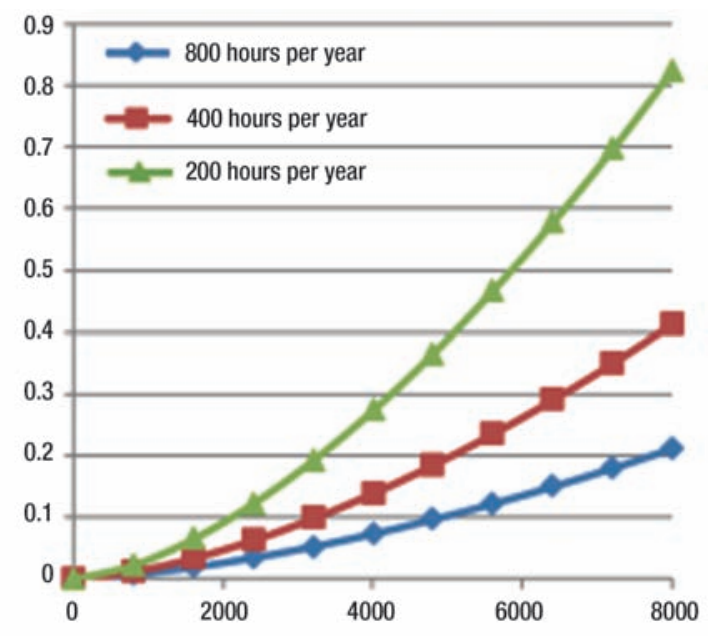

Figure 3. Accumulated repair and maintenance costs as a proportion of the machinery list price for hill-farm tractors under three different operating conditions. maintenance costs, leading eventually to the RMFs of hill-farm tractors and transporters for upland mechanisation, respectively. For this, three different annual utilisations are assumed in each case. For hill-farm tractors, 200, 400 and $800 \mathrm{~h}$ per year are assumed, leading to service lengths of 40, 20 and 10 years, respectively.

Besides the transporters that are built for $10,000 \mathrm{~h}$ of service and the hill-farm tractors that also have an assumed service life of $10,000 \mathrm{~h}$, Table 3 also includes Lips and Burose's (2012) results for standard 4WD

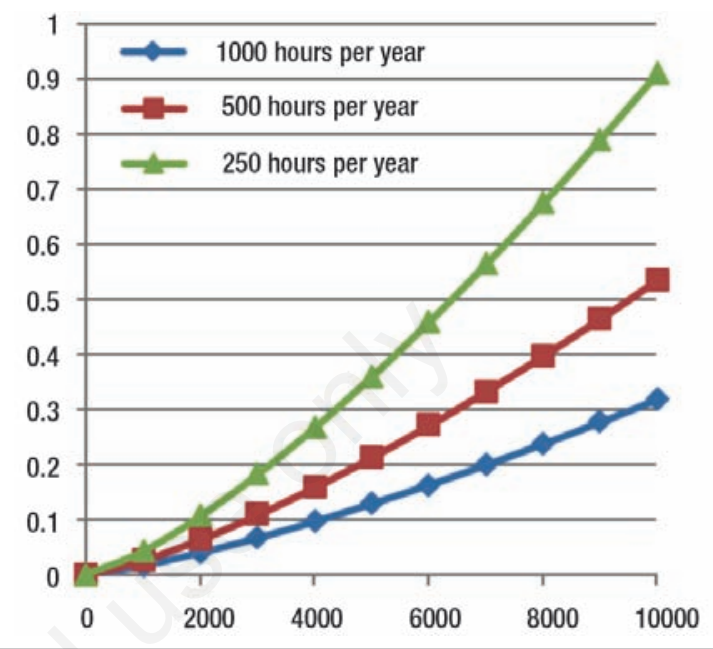

Figure 4. Accumulated repair and maintenance costs for transporters for upland mechanization under three different operating conditions.

Table 2. Regression estimates for annual repair and maintenance costs of hill-farm tractors and transporters for upland mechanisation.*

\begin{tabular}{|c|c|c|c|c|}
\hline & Hill-f & & Transporter & sation \\
\hline & Coeff. & $\mathbf{P}$ & Coeff. & $\mathbf{P}$ \\
\hline Constant & -8.84 & $<0.001$ & -7.97 & $<0.001$ \\
\hline Annual utilisation & 0.59 & $<0.001$ & 0.57 & $<0.001$ \\
\hline Age & 0.61 & $<0.001$ & 0.36 & 0.002 \\
\hline $\mathrm{N}$ & 63 & - & 53 & - \\
\hline $\mathrm{R}^{2}$ & 0.29 & - & 0.33 & - \\
\hline F-test & $12.25(2,60)$ & $<0.001$ & $12.27(2,50)$ & $<0.001$ \\
\hline
\end{tabular}

*Power functional form; $P$, probability that the estimated coefficient is equal to zero.

Table 3. Repair and maintenance factors for different operating conditions.

\begin{tabular}{|c|c|c|c|c|c|c|}
\hline \multirow{2}{*}{ Length of service, years } & \multicolumn{2}{|c|}{ 8000-h service life } & \multicolumn{4}{|c|}{ 10,000-h service life } \\
\hline & $\mathrm{AU}, \mathbf{h}$ & $\begin{array}{l}\text { RMF } \\
\text { hill-farm tractors }\end{array}$ & $\mathrm{AU}, \mathbf{h}$ & $\begin{array}{l}\text { Hill-farm } \\
\text { tractors }\end{array}$ & $\begin{array}{c}\text { RMF } \\
\text { Transporters for } \\
\text { upland mechanisation }\end{array}$ & $\begin{array}{c}\text { Standard 4WD } \\
\text { tractors* }\end{array}$ \\
\hline 10 & 800 & 0.21 & 1000 & 0.24 & 0.32 & 0.26 \\
\hline 15 & 533 & 0.31 & 667 & 0.36 & 0.43 & 0.34 \\
\hline 20 & 400 & 0.41 & 500 & 0.47 & 0.54 & 0.43 \\
\hline 25 & 320 & 0.52 & 400 & 0.59 & 0.63 & 0.50 \\
\hline 30 & 267 & 0.62 & 333 & 0.71 & 0.73 & 0.58 \\
\hline 35 & 229 & 0.72 & 286 & 0.82 & 0.82 & 0.65 \\
\hline 40 & 200 & 0.82 & 250 & 0.94 & 0.91 & 0.72 \\
\hline 45 & 178 & 0.93 & 222 & 1.06 & 1.00 & 0.79 \\
\hline 50 & 160 & 1.03 & 200 & 1.18 & 1.08 & 0.85 \\
\hline
\end{tabular}

AU, annual utilisation; RMF, repair and maintenance factor; accumulated repair and maintenance costs reported in relation to the machine's list price. *According to Lips and Burose (2012). 
tractors. Also the latter have an assumed service life of $10,000 \mathrm{~h}$, as well as an average engine power of $55 \mathrm{~kW}$. The results highlight the impact of annual utilisation on RMF. When a hill-farm tractor is used for $200 \mathrm{~h}$ a year over a 40-year-long (i.e. $8000 \mathrm{~h}$ ) service life, which corresponds exactly to the annual utilisation reported in the sample (Table 1), this results in accumulated repair and maintenance costs (RMFs) of $82 \%$ of the list price. An increase in utilisation towards $229 \mathrm{~h}$ and a corresponding 35 -year length of service reduces the RMF by $10 \%$ of the list price, towards 0.72 . Generally speaking, reducing annual utilisation by half and doubling the length of service (e.g. from 20 to 40 years) increases the accumulated repair and maintenance costs by a factor of at least 1.65 .

Comparing the results of hill-farm tractors and transporters with an estimated service life of $10,000 \mathrm{~h}$, similar values are observed. While hill-farm tractors have lower costs for an annual utilization above 286 $\mathrm{h}$ (lengths of service of 35 years), transporters are relatively less expensive for utilisations under this. A comparison of both hill-farm tractors and transporters to standard $4 \mathrm{WD}$ tractors shows the latter to have distinctly lower RMFs for annual utilisations under $500 \mathrm{~h}$. The results are of the same magnitude for utilisations of $500 \mathrm{~h}$ and above for hill-farm tractors and standard 4WD tractors, while transporters show slightly higher costs.

\section{Discussion}

Since it is not possible to make a direct comparison of our results with those in the literature, several assumptions must be made. Germany's Kuratorium für Technik und Bauwesen in der Landwirtschaft (KTBL; Association for Technology and Structures in Agriculture) gives per-hour repair costs for hill-farm tractors and transporters (KTBL, 2008). We assume that the values given by the KTBL can also be applied to an estimated service life of $10,000 \mathrm{~h}$, which doubles the given service life. Since the KTBL indicates costs separately for several engine-power classes, the average values can be calculated. The Austrian Council for Agricultural Engineering and Rural Development (Österreichisches Kuratorium für Landtechnik und Landentwicklung, ÖKL) reports the repair costs per $100 \mathrm{~h}$ of operation of both machine types under consideration as a percentage of the list price, as well as quoting their annual utilisation (ÖKL, 2009). Since the estimated service life is not stated, we assume a figure of $10,000 \mathrm{~h}$ for both machine types considered.

Assuming an annual utilisation of $417 \mathrm{~h}(10,000 \mathrm{~h}$ within 24 years), the KTBL figures would yield an average RMF of 0.76 for hill-farm tractors. Our results with an annual utilisation of $400 \mathrm{~h}$ are lower (0.59). For hill-farm tractors the ÖKL figures would yield an RMF of 3 , while the annual utilisation varies between engine-power classes by between 150 and $200 \mathrm{~h}$. The results given in this analysis for $200 \mathrm{~h}$ are lower (RMF of 1.18).

As regards transporters for upland mechanisation, the KTBL assumes an annual utilisation of $417 \mathrm{~h}$, which would yield an average RMF of 0.95 . Our results for an annual utilisation of $400 \mathrm{~h}$ are 0.63 . The ÖKL figure gives an RMF of 2 for an annual utilisation of between 250 and 275 h. Our results are clearly lower: 0.91 and 0.82 for 250 and 286 $\mathrm{h}$, respectively.

Our RMF results must be interpreted as minimum values. As indicated above, on-farm work input for repair activities was not addressed in the survey. Consequently, working time cannot be rated, which leads to an underestimation of annual repair and maintenance costs. Furthermore, we cannot rule out the possibility that farm managers have forgotten to report some costs.

Both regressions for the annual cost function account for approxi- mately $30 \%$ of the variance, raising the question of other important influences on repair and maintenance costs not covered in the data used. In addition, the make of the machinery, additional equipment, and operating conditions might differ significantly from machine to machine in the samples. Further potential influences are how farm workers treat the machinery, as well as the quality and regularity of machine servicing. Lastly, as pointed out by Calcante et al. (2013), engine load is also important.

\section{Conclusions}

This paper analyses the repair and maintenance costs of two specific motorised agricultural machines for upland agriculture in Switzerland: hill-farm tractors (two-axle mowers) and transporters for upland mechanisation. The regressions explaining the annual repair and maintenance costs show the influence of both annual utilisation and the machine's age. The estimated coefficients indicate that an increase in annual utilisation leads to a disproportionate low increase in repair and maintenance costs. This effect is also crucial for the accumulated repair and maintenance costs for the entire service life of the machine, given as repair and maintenance factors. Assuming that the estimated service life is completely utilised, a high annual utilisation will reduce the accumulated repair and maintenance costs.

Because of the limitations of the data used, as well as the fact that only a limited percentage of the variance can be explained by regression analysis, the RMFs quoted here must be understood as minimum figures. We recommend rounding up the RMFs when applying them to farm-management literature.

Our results are lower than those in the literature. While the differences with German indications are relatively small (especially for hillfarm tractors), they are less than half of the reference from Austria. The indications from Austria seem to be rough estimates and are clearly higher than the German values. There are at least two possible reasons for the differences between our results and those from Germany. Firstly, as explained above, our results must be rounded up. Secondly, assuming that the German repair and maintenance cost figures apply to analyses carried out at least a decade ago, the differences observed might be attributable to technical progress. Analysing the repair costs of German tractors and combines, Bruhn (2000) discovered a falling trend for costs over time. It would, therefore, be extremely useful to repeat the analysis in a few years to check for technical improvement. Moreover, there is a further need for repair and maintenance cost analyses for other types of machines for upland agriculture, such as motor mowers (walking tractors).

A comparison of the resulting RMFs of hill-farm tractors to those of standard 4WD tractors shows that both machine types have the same magnitude for high-level annual utilisation of $500 \mathrm{~h}$ or more. Transporters for upland mechanisation show slightly higher costs for such utilisations. For lower annual utilisations, such as the $200 \mathrm{~h}$ per year found for both machine types under consideration, the RMFs of standard 4WD tractors are significantly lower. We, therefore, conclude that it is not recommended to assume that the RMFs of hill-farm tractors and transporters are equivalent to those of a standard 4WD tractor.

As regards a cross-comparison between standard 4WD tractors on the one hand and hill-farm tractors and transporters on the other, absolute repair and maintenance costs are not only dependent on the RMFs, but also on the machines' list prices. Both machines types in question are more expensive in terms of cost per $\mathrm{kW}$ engine power. Assuming similar engines and the usual operating version used for approximately $200 \mathrm{~h}$ per year, we conclude that per-hour repair and maintenance costs are significantly lower for standard 4WD tractors 
than for hill-farm tractors and transporters for upland mechanisation. This is interesting for farmers contemplating the replacement of hillfarm tractors or transporters by standard 4WD tractors or the purchase of additional equipment such as a self-loading trailer.

\section{References}

Albisser G., Gazzarin C., Gärtner D. 2009. Maschinenkosten in der Praxis: Auslastung, Nutzungsdauer und Reparaturkosten ausgewählter Landmaschinen auf Schweizer Betrieben. ART-Bericht No. 711. Agroscope Reckenholz-Tänikon Research Station ART, Ettenhausen, Switzerland.

Ammann H. 2007. Maschinenkosten 2008, ART-Bericht No. 688. Agroscope Reckenholz-Tänikon Research Station ART, Ettenhausen, Switzerland.

ASAE. 2003a. Agricultural Machinery Management Data D497.4 FEB03. American Society of Agricultural Engineers, St. Joseph, MI, USA.

ASAE. 2003b. Agricultural Machinery Management EP496.2 FEB03. American Society of Agricultural Engineers, St. Joseph, MI, USA.

Bruhn I. 2000. Erhebung zu Reparaturkosten von Maschinen auf Grossbetrieben, dargestellt für Traktoren und Mähdrescher. Forschungsbericht Agrartechnik No. 357. Diss., ChristianAlbrechts-University Kiel, Germany.

Bowers W., Hunt D.R. 1970. Application of mathematical formulas to repair cost data. Trans. ASAE 13:806-9.

Calcante A., Fontanini L., Mazzetto F. 2013. Repair and maintenance costs of 4WD tractors in Northern Italy. Trans. ASABE 56:355-62.

Eichhorn H. (ed.). 1999. Landtechnik, landwirtschaftliches Lehrbuch, 7th ed. Verlag Eugen Ulmer, Stuttgart, Germany.

Gazzarin C., Albisser G. 2010. Maschinenkosten 2010. ART-Bericht No. 733. Agroscope Reckenholz-Tänikon Research Station ART, Ettenhausen, Switzerland.

Khoub bakht G.M., Ahmadi H., Akram A., Karimi M. 2008. Repair and maintenance cost model for MF285 tractor: a case study in central region of Iran. Am-Euras. J. Agric. Environ. Sci. 4:76-80.

KTBL. 2008. Betriebsplanung Landwirtschaft 2008/09, Daten für die Betriebsplanung in der Landwirtschaft, 21st ed. Kuratorium für Technik und Bauwesen in der Landwirtschaft (Association for Technology and Structures in Agriculture), Darmstadt, Germany.

Lips M., Burose F. 2012. Repair and maintenance costs for agricultural machines. Int. J. Agric. Manage. 1:40-6.

Lips M. 2013. Repair and maintenance costs for nine agricultural machine types. Trans. ASABE 56:1299-307.

Morris J. 1988. Tractor repair costs. Farm Manage. 6:433-41.

ÖKL, 2009. ÖKL-Richtwerte für die Maschinenselbstkosten, Österreichisches Kuratorium für Landtechnik und Landentwicklung (Austrian Council for Agricultural Engineering and Rural Development), Vienna, Austria.

Rotz C.A. 1987. A standard model for repair costs of agricultural machinery. Appl. Eng. Agric. 3:3-9.

Ward S.M., McNulty P.B., Cunney M.B. 1985. Repair costs of 2 and 4 WD tractors. Trans. ASAE 28:1074-6.

Wendel G. 1989. Reparaturkostenuntersuchungen an Ackerschleppern. Grundl. Landtechnik 39:17-21. 